\title{
Impaired pubertal growth in acute lymphoblastic leukaemia
}

\author{
M Uruena, R Stanhope, J M Chessells, A D Leiper
}

\begin{abstract}
The growth of 182 patients who were long term survivors of childhood acute lymphoblastic leukaemia was retrospectively analysed. All remained in first remission and were treated with either 1800 or $2400 \mathrm{cGy}$ of cranial irradiation. None had been treated with either testicular or spinal irradiation. Ninety three (51 boys, 42 girls) were treated with 2400 cGy and 89 (42 boys, 47 girls) were treated with 1800 cGy cranial irradiation. All patients were treated with standard chemotherapy including intrathecal methotrexate in similar dose regimens in either group. Mean age (SD) at diagnosis in the group treated with 2400 cGy was $4.8(2.6)$ years and mean age in the group treated with 1800 cGy was 6.5 (3.3) years. Mean height SD score at diagnosis in the $\mathbf{2 4 0 0}$ cGy group was +0.29 and final height achieved was -0.63 . Mean height SD score at the start of treatment in the group treated with 1800 cGy was +0.40 and mean final height was -0.53 . There was a similar reduction in height SD score in both groups during the pubertal growth spurt.

The decrement in height SD score was greater when treatment was administered at less than 7 years of age in either dose regimen, both in prepubertal and pubertal growth. However, the decrease in height SD score was found to be greater in girls than boys. There was a trend in both sexes for the onset of puberty to be at a younger age with a lower treatment dose of radiotherapy. However, in girls treated with the lower dose regimen there was a significant reduction in the mean age of onset of puberty which was $\mathbf{9 . 9}$ years. Our data suggest that girls treated at less than 7 years of age have a severe impairment of pubertal growth, which is probably a combination of the dual endocrinopathy of premature puberty and growth hormone insufficiency.
\end{abstract}

Long term survival for children with acute lymphoblastic leukaemia has improved enormously in recent years, partly due to the introduction of treatment to the central nervous system, ${ }^{12}$ which is given as a combination of intrathecal methotrexate and cranial irradiation. ${ }^{3}$ Because of the morbidity of cranial irradiation, the dose administered has been reduced in recent years from $2400 \mathrm{cGy}$ in 15 fractions over three weeks to $1800 \mathrm{cGy}$ in 10 fractions over two weeks. $^{4}$

Cranial irradiation may cause pituitary dysfunction, of which growth hormone insufficiency is the most common endocrinopathy. This is related to both the administered dose of irradiation and the method of fractionation. ${ }^{56}$ The effect of the irradiation is delayed and progressive. It has been reported that regimens of low dose cranial irradiation may cause growth hormone insufficiency and growth failure ${ }^{78}$ in children with acute lymphoblastic leukaemia. The degree of growth suppression and whether this requires growth hormone replacement treatment has been controversial. ${ }^{910}$ Recent data have even suggested that final height is not altered in children treated for acute leukaemia. ${ }^{11}$ Low dose cranial irradiation in children with acute lymphoblastic leukaemia has been reported to be associated with central premature and precocious puberty, ${ }^{12-14}$ predominantly affecting girls. ${ }^{15}$ However, the significance of this for ultimate height is unknown.

Between 1970 and 1980 the dose of cranial irradiation administered was $2400 \mathrm{cGy}$ but this was superseded in 1981 by a dosage of 1800 cGy. During the last 20 years treatment has altered in that induction and consolidation has become more intensive. However the basic drugs used, including intrathecal methotrexate and maintenance treatment (6-mercaptopurine, methotrexate, prednisolone, and vincristine), have essentially remained unaltered. We have been able to compare the onset of puberty and the pubertal growth spurt in children treated by either of these two irradiation dose regimens.

\section{Patients and methods \\ PATIENTS}

Data from 182 patients were analysed in this study from a total cohort of 307 patients who were survivors of acute lymphoblastic leukaemia diagnosed at the Hospital for Sick Children between 1970 and $1986 .{ }^{16}$ All patients were in first remission, had been off treatment for two years or more, and had attained the onset of puberty at the time of this study. None had received gonadal or spinal irradiation. Twelve children (seven treated with $1800 \mathrm{cGy}$, five treated with $2400 \mathrm{cGy}$ ) were treated with growth hormone and/or gonadotrophin releasing hormone (GnRH) analogue during the course of this study and were excluded, as well as those with dysmorphic syndromes or abnormal karyotypes.

Ninety three patients ( 51 boys, 42 girls) were treated with $2400 \mathrm{cGy}$ cranial irradiation and 89 (42 boys, 47 girls) were treated with $1800 \mathrm{cGy}$. Cranial irradiation was usually given within eight weeks of diagnosis or occasionally delayed until the patient was 2 years of age. Chemotherapy regimens have been previously 
described. ${ }^{17-19}$ The numbers of patients at diagnosis, onset of puberty, and final height are indicated in fig 1 . Because the group treated with 2400 cGy was before 1980 , a much larger number of patients had attained final height than in the lower dose group.

\section{METHODS}

Clinical records of the patients were examined retrospectively including height obtained at diagnosis (equivalent to the onset of treatment), the onset of puberty, and final height. Stature was expressed as SD scores with comparison of data from Tanner et al. ${ }^{20}{ }^{21}$ No adjustment was made for secular trend in height. The onset of puberty was taken as the acquisition of breast development in girls (B2) and the development of either stage 2 genitalia and/or $4 \mathrm{ml}$ testicular volume in boys. Normal data for the ages of attainment of sexual maturation were from Marshall and Tanner. ${ }^{22} 23$ The patients were divided into two groups according to the two dose regimens of cranial irradiation used as well as the age at onset of acute lymphoblastic leukaemia. Statistical measurements were performed using paired and independent $t$ test.

\section{Results}

Data for change of height SD score during puberty are shown in fig 1 . The pattern of reduction of height $\mathrm{SD}$ score during both prepuberty and puberty was similar in both groups. However, this was not significant in the 1800 cGy irradiation group, which probably reflects the smaller proportion of patients who had attained final height. Age at onset of puberty was greater by 0.4 years in the children treated with the higher dose regimen but this may be a reflection of a secular trend.

The decrement in height SD score, especially $\stackrel{\widehat{\partial}}{\supset}$ during puberty, was greater when cranial irradiation was administered at less than 7 years of age in both dose regimens (fig 2). In contrast, children treated for acute lymphoblastic leukaemia at the age of 7 years or above were more

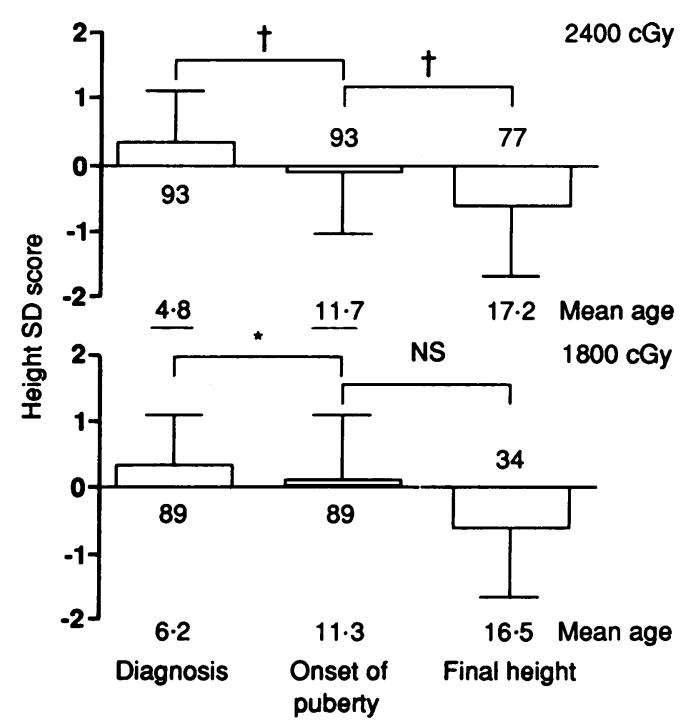

Figure 1 Growth data for 182 children treated for acute lymphoblastic leukaemia with either 2400 or 1800 cGy cranial irradiation. Height $S D$ score at diagnosis, at the onset of puberty, and at final height are shown. Horizontal bars represent ISD. ${ }^{*}=p<0.005, t=p<0.0001, N S=$ not significant. The number of patients are indicated.

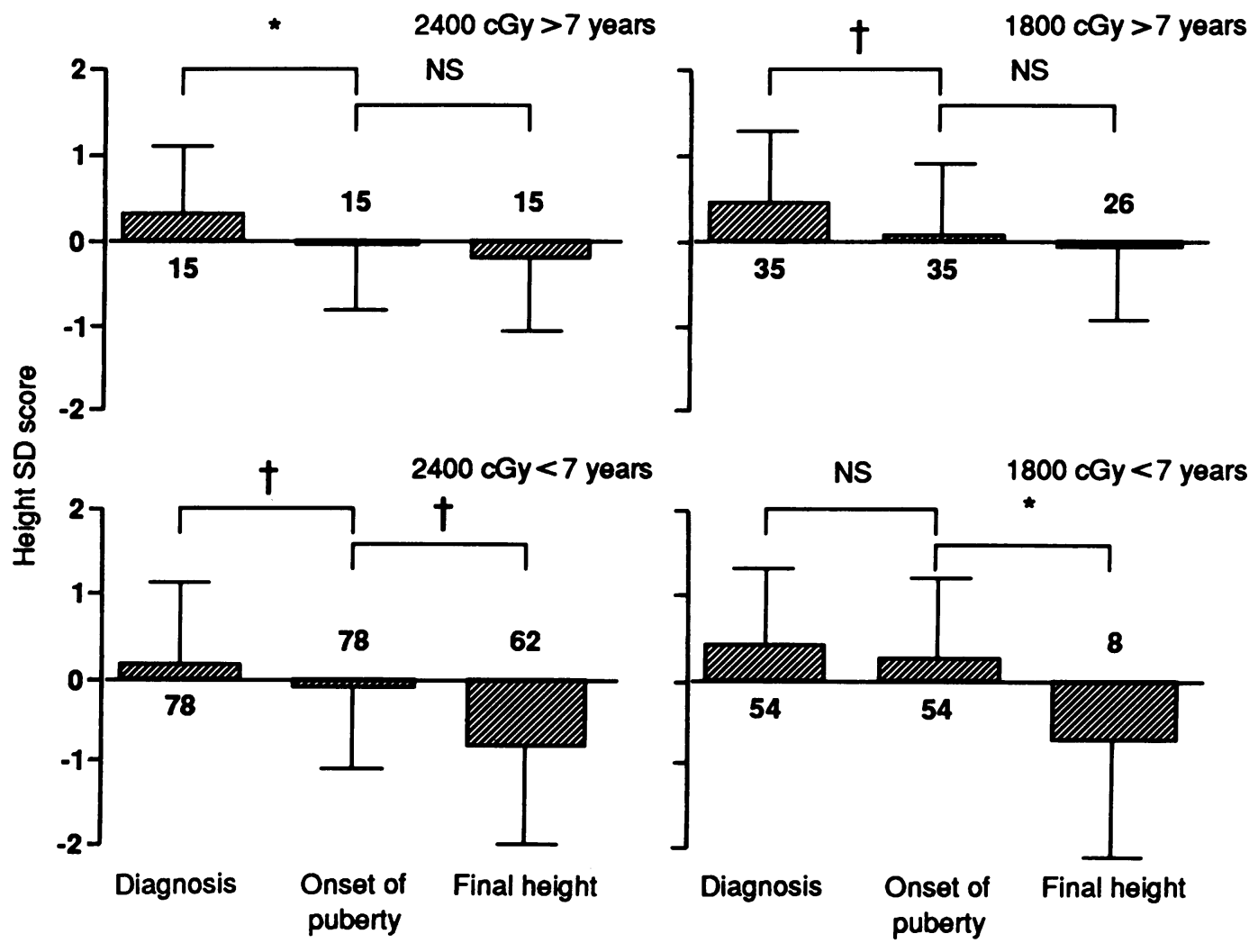

Figure 2 Height SD score in 182 children with acute lymphoblastic leukaemia treated with cranial irradiation (2400 cGy or $1800 \mathrm{cGy}$ ), before and after 7 years of age. Horizontal bars represent $1 S D .{ }^{*}=p<0 \cdot 005, t=p<0 \cdot 0001, N S=$ not significant. The number of patients are indicated. 


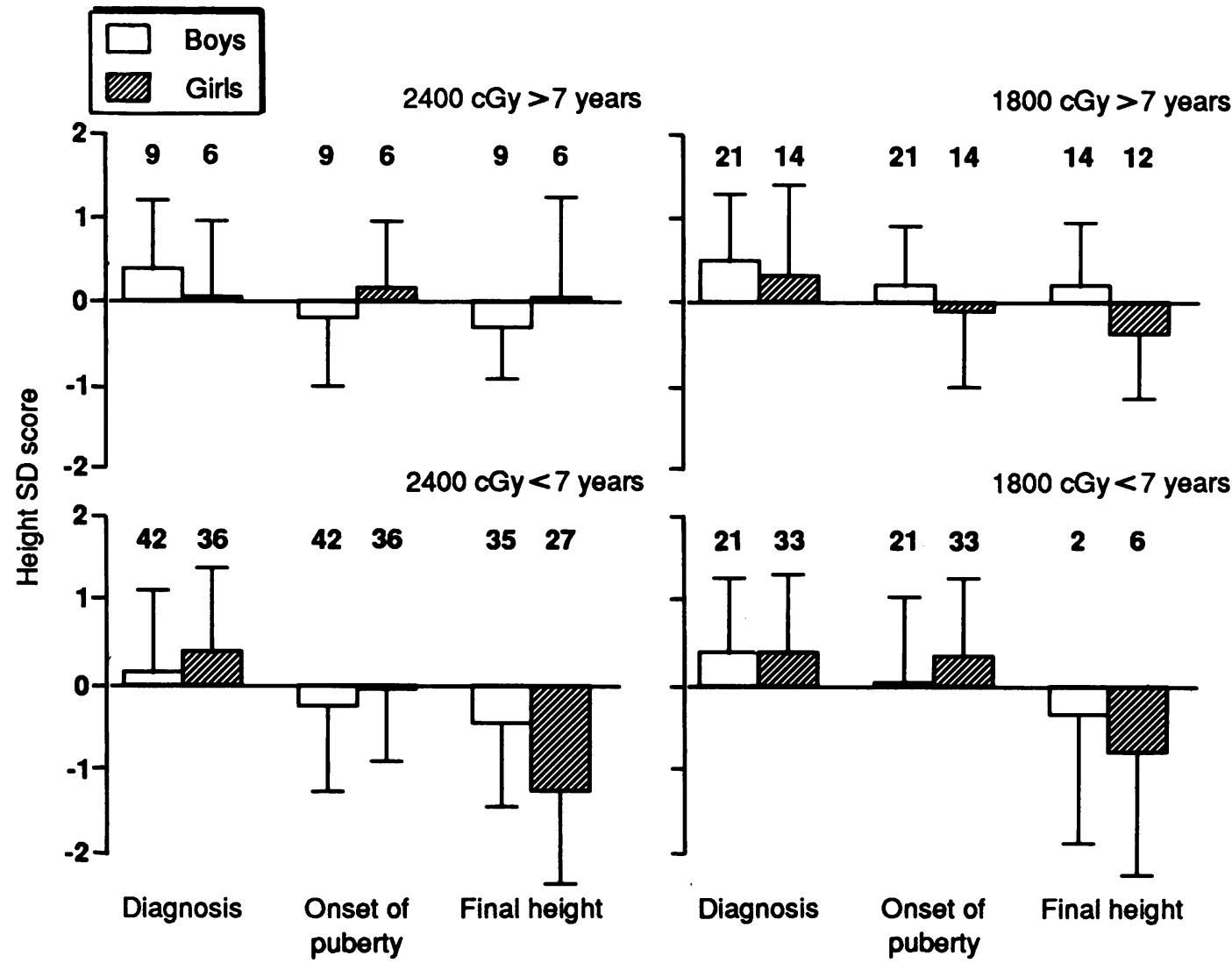

Figure 3 Height SD score in 93 (51 boys, 42 girls) and 89 (42 boys, 47 girls) patients treated for acute lymphoblastic leukaemia with $2400 \mathrm{cGy}$ and 1800 cGy cranial irradiation respectively, before and after 7 years of age. Horizontal bars represent ISD. The number of patients are indicated.

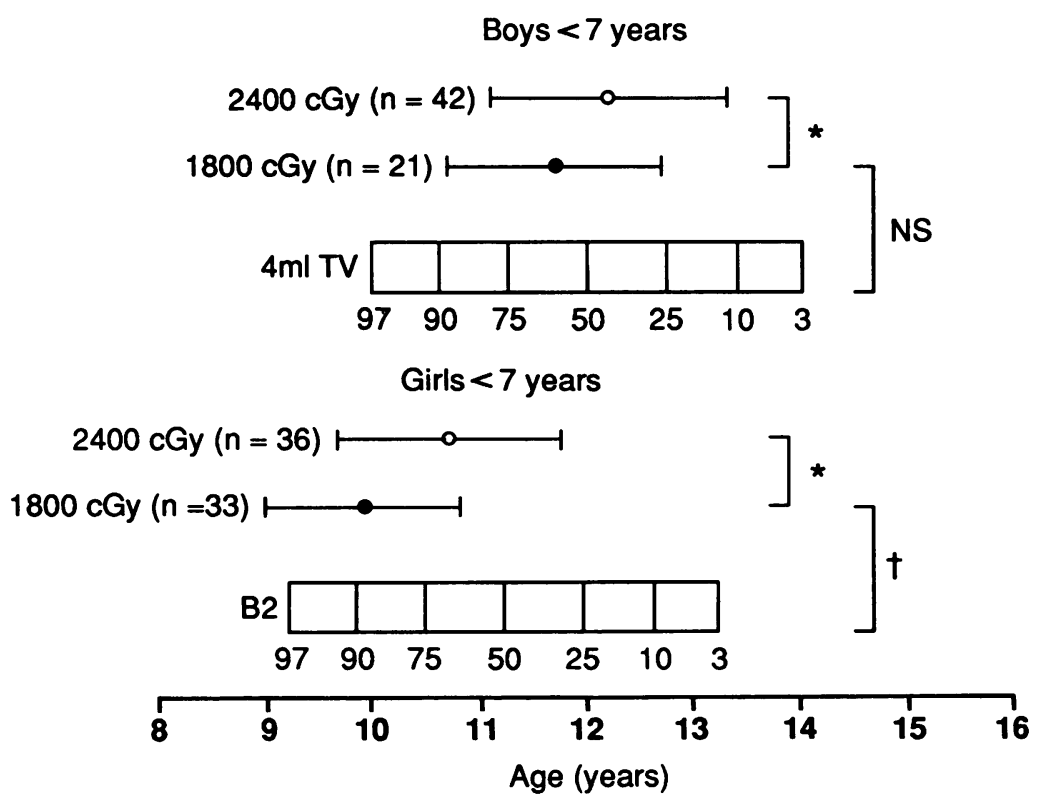

Figure 4 Age at the onset of puberty in 69 girls (B2) and 63 boys ( 4 ml testicular volume) treated for acute lymphoblastic leukaemia under the age of 7 years with either of two dose regimens of cranial irradiation (2400 or 1800 cGy). Vertical bars represent $1 S D$. Data for normal girls and boys from Marshall and Tanner $1969^{22}$ and $1970^{23}$ respectively.

${ }^{*}=p<0 \cdot 001, t=p<0.0001, N S=$ not significant. B2, breast stage $2 ; T V$, testicular volume. affected during prepubertal growth in both irradiation groups. Differences between height SD score at onset of puberty and final height were not significant (fig 2). Girls were more affected than boys in both dose regimens, but the number of patients in each group attaining final height was small (fig 3 ).

In order to study the effects of cranial irradiation on pubertal development, we have excluded children treated for acute lymphoblastic leukaemia at greater than 7 years of age. Mean age (SD) at onset of puberty in the $2400 \mathrm{cGy}$ group was $12.2(1.0)$ years in boys and 10.6 $(1 \cdot 0)$ years in girls. By contrast, mean age at onset of puberty in the 1800 cGy group was 11.4 $(1.5)$ years in boys and $9.9(0.9)$ years in girls (fig 4). Surprisingly the onset of puberty with the lower dose was earlier in both sexes $(\mathrm{p}<0.01)$, and a significant difference was found in comparison with the mean of the British population for girls $(\mathrm{p}<0.0001)$, but not for boys.

\section{Discussion}

The main difficulty in the interpretation of this study arises from the fact that we have compared different treatment groups from 1970 until 1986 , and this study is in series and not in parallel. No adjustment has been made for secular change in either stature or for the timing of puberty. However we believe that, even considering these difficulties, our data are relevant. Furthermore the exclusion of 12 patients who received endocrine treatment for 
growth failure increases the significance of our findings. Broomhall and colleagues demonstrated in a large number of patients that children with acute lymphoblastic leukaemia were significantly taller than the normal population with a mean SD score of $+0 \cdot 49 .^{24}$ We found that at diagnosis our patients were taller than average. A possible explanation is that leukaemia is a disease of the higher social classes and the latter have greater than average stature. ${ }^{25}$

It is appreciated that the treatment of brain tumours with high dose cranial irradiation is associated with a high incidence of growth hormone insufficiency/deficiency. ${ }^{5}$ In our data the decrement in final height was similar with both $2400 \mathrm{cGy}$ and $1800 \mathrm{cGy}$ cranial irradiation. Our observations are in agreement with Shalet in that the initial endocrinopathy associated with cranial irradiation is growth hormone insufficiency. ${ }^{5}$ It has been reported by previous authors that growth hormone secretion in young children is more sensitive to damage by a given dose of irradiation than in older children. ${ }^{26}$ The effects of irradiation on pituitary function tend to be delayed and progressive over several years. ${ }^{5}$ Certainly children treated with cranial irradiation under the age of 7 years have a higher incidence of growth failure than older children ${ }^{26}$ and our data are in agreement with this.

Cranial irradiation of either 2400 or $1800 \mathrm{cGy}$ affects growth in prepuberty as well as in puberty. In normal children growth in prepuberty is a continuous deceleration, and there is evidence of a progressive decrease in growth hormone secretion until the onset of the growth spurt. ${ }^{28}$ During the pubertal growth spurt growth is dependent on both sex steroids and growth hormone and one without the other produces an inadequate growth acceleration. ${ }^{29}$ It has been suggested that growth hormone secretion in children treated with low dose cranial irradiation is predominantly decreased during puberty rather than prepuberty. ${ }^{30}$ Our data suggest that overall, prepubertal growth is affected almost as much as pubertal growth, but when the groups were subdivided by age, a different picture emerged. There was a significant decrease in height SD score between the onset of puberty and final height attainment in both radiation groups diagnosed under the age of 7 years, but not during prepubertal growth in the 1800 cGy group. This suggests that the larger dose of 2400 cGy affected both prepubertal and pubertal growth but 1800 cGy given at a young age predominantly caused loss of the growth spurt. Of course, the majority of the population with leukaemia are diagnosed under the age of 7 years and indeed in this study the onset of leukaemia was below this age in $72 \%$ of the children. The latter situation of impairment of the pubertal growth spurt in those children receiving $1800 \mathrm{cGy}$ at less than 7 years of age will thus be the commonest prevailing picture at the present time.

Recent data have suggested that low dose cranial irradiation is associated with precocious or early puberty in girls rather than boys and our present analysis support this. Of interest from our study is the suggestion that earlier puberty is the result of the lower dose regimen of $1800 \mathrm{cGy}$ rather than $2400 \mathrm{cGy}$ cranial irradiation. Certainly early puberty could be a contributory reason as to why growth impairment in the girls was greater than in the boys. Alternatively it may also be that growth hormone secretion is more adversely affected in girls than boys in the same way that gonadotrophin secretion is affected differently between the sexes. We know no other supportive data for such a hypothesis. The most important single group to identify therefore is girls treated at a young age as they show the greatest degree of growth retardation. As well as the possibility of growth hormone treatment for this group, it may be advantageous to therapeutically manipulate the timing of pubertal maturation using a GnRH analogue. There is now some evidence to suggest that a combined regimen of both growth hormone and GnRH analogue may be advantageous. ${ }^{15}$

In conclusion, we suggest that all children who are treated for acute lymphoblastic leukaemia with cranial irradiation, especially girls treated at a young age, have their growth carefully monitored both during prepuberty and especially during puberty. Certainly the growth failure induced by cranial irradiation at a low dose regimen may be significant and require appropriate treatment. Our data indicate which groups of children by age and sex are likely to require special attention.

Dr Uruena was supported by a grant from Eli Lilly, Basingstoke. Dr Leiper receives a grant from the Medical Research Council. Secretarial support for the preparation of the manuscript was provided by Serono (UK)

1 Pinkerton CR, Chessells JM. Failed central nervous system prophylaxis in children with acute lymphoblastic leukaemia: treatment and outcome. Br $\mathcal{H}$ Haematol 1984;57:553-61.

2 Birch JM, Marsden HB, Morris-Jones PH, Pearson D, Blair U. Improvements in survival from childhood cancer: results of a population based survey over 30 years. BMF 1988;296 $1372-6$

3 Hustu HO, Aur RJA, Versosa MS, Simone JV, Pinkel D. Prevention of central nervous system leukaemia by irradiation. Cancer 1973;32:585-97.

4 Shalet SM, Beardwell CG, Morris-Jones PH, Pearson D. Growth hormone deficiency after treatment of acute leukaemia in children. Arch Dis Child 1976;51:489-93.

5 Shalet SM. Irradiation-induced growth failure. Clinics in Endocrinology and Metabolism 1986;15:591-606.

6 Cowell CA, Quigley B, Moore JA, et al. Growth and growth hormone therapy of children treated for leukaemia. Acta hormone therapy of children treated for

7 Kirk J, Stevens MM, Monser MA, et al. Growth failure and growth hormone deficiency after treatment for acute growth hormone deficiency after treatmen
lymphoblastic leukaemia. Lancet 1987;i:190-3.

8 Clayton PE, Shalet SM, Morris-Jones PH, Price DA. Growth in children treated for acute lymphoblastic leukaemia. Lancet 1988;

9 Shalet SM, Price D, Beardwell C. Normal growth despite abnormalities of growth hormone secretion in childre treated for acute leukaemia. I Pediatr 1979;94:719-22.

10 Voorhess M, Brecher ML, Glickaman AS, et al. Hypothalamic pituitary function of children with acute lymphoblastic leukaemia after three forms of central nervous system prophylaxis. Cancer 1986;57:1287-91.

11 Bramswig JH, Zielinski G, Schellong G. Adult height, target height and siblings adult height in 107 patients treated for acute lymphoblastic leukaemia (ALL). Comparison of the effects of four different chemotherapy regimens and different doses of cranial irradiation. Horm Res 1990;33 (suppl 3):32.

12 Brauner R, Czernichow P, Rappaport R. Precocious puberty after hypothalamic and pituitary irradiation in young after hypothalamic and pituitary irrad

13 Moell C. Disturbed pubertal growth in girls after acute lymphoblastic leukaemia: a relative growth hormone insufficiency with late presentation. Act Paediatr Scand 1988;343 (suppl): 162-6.

14 Leiper AD, Stanhope R, Kitching P, Chessells JM. Precocious and premature puberty associated with treatment of acute lymphoblastic leukaemia. Arch Dis Child 1987;62 1107-12. 
15 Leiper AD, Stanhope R, Preece MA, Grant DB, Chessells JM. Precocious or early puberty and growth failure in girls
treated for acute lymphoblastic leukaemia. Horm Res 1988; treated for

16 Stanhope R, Uruena $M$, Hindmarsh P, Leiper AD, Brook CGD. Management of growth hormone deficiency through puberty. Acta Paediatr Scand 1991;[suppl]372:47-52.

17 Chessells JM. Some aspects of treatment of childhood leukaemia. In: Valman HB, eds. Topics in paediatrics 3. Recen advances in paediatric therapeutics. London: Pitman Medical, 1982:129-38

18 Chessells JM, Leiper AD, Tiedemann K, Hardisty RM. Oral methotrexate is as effective as intramuscular methotrexate in maintenance therapy of acute lymphoblastic leukaemia. Arch Dis Child 1987;62:172-6.

19 Pinkerton CR, Bowman A, Holtzel H, Chessells JM. Intensive consolidation chemotherapy for acute lymphoblastic leu12-8.

20 Tanner JM, Whitehouse RH, Takaishi $M$. Standards for birth to maturity for height, weight, height velocity, and weight to maturity for height, weight, height velocity, and weight
velocity: British children, 1965. Part I. Arch Dis Child 1966; velocity: Britis
41:454-71.

21 Tanner JM, Whitehouse RH, Takaishi M. Standards for birth to maturity for height, weight, height velocity, and weight velocity: British children, 1965. Part II. Arch Dis Child 1966;41:613-35.
22 Marshall WA, Tanner JM. Variations in pattern of pubertal changes in girls. Arch Dis Child 1969;44:291-303.

23 Marshall WA, Tanner JM. Variations in pattern of pubertal changes in boys. Arch Dis Child 1970;45:13-23.

24 Broomhall J, May R, Lilleyman JS, Milner RDG. Height and lymphoblastic leukaemia. Arch Dis Child 1983;58:300-1.

25 McWhirter WR. The relationship of incidence of childhood $\stackrel{\rho}{\partial}$ lymphoblastic leukaemia to social class. $\mathrm{Br} \mathcal{F}$ Cancer 1982 ; 46:640-6.

26 Brauner R, Czernichow P, Rappaport R. Greater susceptibility to hypothalamo-pituitary irradiation in younger children with acute lymphoblastic leukaemia. I Pediatr 1986;108: 긍

27 Berglund G, Karlberg J, Marky I, Mellander L. A longitudinal study of growth in children with acute lymphoblastic $\overline{\overline{\vec{S}}}$ leukaemia. Acta Paediatr Scand 1985;74:530-3.

28 Hindmarsh P, Smith PJ, Brook CGD, Matthews DR. The relationship between height velocity and growth hormone $\bar{O}$ secretion in short prepubertal children. Clin Endocrinol $\overline{\bar{N}}$ (Oxf) 1987;27:581-91.

29 Aynsley-Green A, Zachmann M, Prader A. Interrelation of $\mathbb{D}$ the therapeutic effects of growth hormone and testosterone the therapeutic effects of growth hormone and testostero

30 Crowne EC, Wallace WHB, Moore C, Shalet SH, MorrisJones PH, Price DA. Pubertal rise in spontaneous growth $\vec{O}$ hormone (GH) secretion is attenuated by low-dose irradiation. Horm Res 1990;33(suppl 3):36.

\section{... and while on the subject}

Accepted treatment for Kawasaki disease is with aspirin and intravenous gammaglobulin. An American multicentre randomised trial reported in 1986 showed that coronary artery dilatations were less common after treatment with gammaglobulin and aspirin than after aspirin alone. ${ }^{1}$ In that trial the gammaglobulin was given as four consecutive daily doses of $400 \mathrm{mg} / \mathrm{kg}$ body weight. Now the same workers have shown that a single infusion of $2 \mathrm{~g} / \mathrm{kg}$ is equally if not more, effective (Jane W Newburger and colleagues, New England Fournal of Medicine 1991;324:1633-9). Clinical and laboratory indices of inflammation also resolved quicker with the single large dose.

An editorial in the same issue of the journal points out that there are still unresolved questions. ${ }^{2}$ The main end point in these trials has been coronary dilatation of any severity seen on echocardiography. Dilatation of less than $6 \mathrm{~mm}$ is apparently relatively benign and it is the giant aneurysms which lead to myocardial infarction and death. The effect of gammaglobulin on mortality is not known. Nevertheless in the most recent trial none of the 254 children who had normal coronary arteries when first seen and who received the single large infusion of gammaglobuin developed giant aneurysms. All of the patients in this study were treated within 10 days of the onset of the disease. The effect of treatment later in the course of the disease in unknown but it seems reasonable to treat if the disease process is still active. ${ }^{2}$

The role of aspirin is uncertain. Continuous low dose aspirin seems indicated if there is persisting coronary abnormality but whether initial high dose treatment is necessary is not known.

\section{ARCHIVIST}

1 Newburger JW, Takahashi M, Burns JC, et al. The treatment of Kawasaki syndrome with intravenous gamma globuin. N Engl f Med 1986;315:341-7.

2 Shackelford PG, Strauss AW. Kawasaki syndrome. N Engl f Med 1991;324:1664-6. 